\title{
Perbandingan Efek Analgesia antara Fentanil dan Oksikodon Intravena untuk Pengelolaan Nyeri Pascabedah Laparotomi Kolesistektomi
}

\author{
Thomas, Iwan Fuadi, Iwan Abdul Rachman \\ Departemen Anestesiologi dan Terapi Intensif \\ Fakultas Kedokteran Universitas Padjajaran/RSUP Dr. Hasan Sadikin Bandung
}

\begin{abstract}
Abstrak
Nyeri pascabedah harus diatasi dengan baik menggunakan analgetik yang memiliki efek analgesia adekuat dengan efek samping minimal. Penelitian ini bertujuan mengetahui perbedaan nyeri pascabedah laparotomi kolesistekomi yang dinilai dengan numeric rating score (NRS) antara pasien yang menggunakan continuous intravenous patient controlled analgesia (IV-PCA) fentanil dan oksikodon. Penelitian dilakukan pada periode Agustus-November 2020 di RSUP dr. Hasan Sadikin Bandung. Penelitian randomized control trial (RCT) dilakukan terhadap 32 subjek status fisik ASA I-II yang terbagi menjadi dua kelompok, yaitu kelompok yang mendapat continuous IV-PCA fentanil 0,5 $\mu \mathrm{g} / \mathrm{kgBB} / \mathrm{jam}$ dan kelompok dengan continuous IV-PCA oksikodon $30 \mu \mathrm{g} / \mathrm{kgBB} / \mathrm{jam}$. Nyeri pascabedah dinilai dengan NRS pada jam pertama, ke-6, ke-12, dan ke-24. Analisis statistik data numerik dengan Uji Mann-Whitney, data kategorik dengan uji chi-square dan alternatif Uji Fisher's Exact. Nilai NRS pada kelompok oksikodon lebih rendah dibanding dengan fentanil pada jam pertama hingga jam ke-24 ( $\mathrm{p}=0,001)$. Kebutuhan rescue analgetik pada jam pertama dan ke-6 juga lebih rendah pada kelompok oksikodon ( $\mathrm{p}=0,012 ; \mathrm{p}=0,022$, berurutan). Penelitian dengan rasio fentanil:oksikodon 1:60 ini tidak menunjukkan perbedaan efek samping kejadian mual, muntah, pusing, sakit kepala, dan pruritus antara kedua kelompok. Pemberian analgesia oksikodon intravena pada pasien pascabedah laparotomi kolesistektomi lebih baik dibanding dengan fentanil intravena.
\end{abstract}

Kata kunci: Fentanil, laparotomi kolesistektomi, nyeri pascabedah, oksikodon

\section{Comparison of Analgesia Effect between Intravenous Fentanyl and Oxycodone for Postoperative Pain Management after Laparotomy Cholecystectomy}

\begin{abstract}
Postoperative pain must be addressed properly with adequate analgetic drugs and minimal side effects. This study aimed to determine the differences in postoperative cholecystecomy laparotomy pain assessed by NRS in patients receiving continuous PCA fentanyl or oxycodone. This was a randomized clinical trial on 32 subjects between August-November 2020 at dr. Hasan Sadikin Hospital Bandung. These subjects were divided into two groups: the group that received continuous intravenous infusion of PCA fentanyl $0.5 \mu \mathrm{g} / \mathrm{kgBW} / \mathrm{hour}$ and the group with continuous intravenous infusion of PCA oxycodone $30 \mu \mathrm{g} / \mathrm{kgBW} /$ $\mathrm{hr}$. Thepostoperative pain was assessed by NRS at the 1st, 6th, 12th, and 24th hours. Statistical analysis of numerical data was performed using the Mann-Whitney test while the categorical data were analyzed using Chi-Square test with alternative uji Fisher's Exact test. Results showed that NRS was lower in the oxycodone group than in the fentanyl group at the first to 24 hours $(p=0.001)$. The need for analgesic rescue at the first and sixth hours was also lower in the oxycodone group ( $\mathrm{p}=0.012 ; \mathrm{p}=0.022$, respectively). The observation of opioid side effects on fentanyl:oxycodone with a ratio of 1:60 did not present any difference in the incidence of nausea, vomiting, dizziness, headache, and pruritus in both groups. The administration of intravenous oxycodone in postoperative cholecystectomy laparotomy patients gives better analgesia effect than intravenous fentanyl.
\end{abstract}

Keywords: Fentanyl, laparotomy cholecystectomy, postoperative pain, oxycodone

Korespondensi: Thomas, dr., Departemen Anestesiologi dan Terapi Intensi Fakultas Kedokteran Universitas Padjadjaran/ RSUP Dr. Hasan Sadikin Bandung, Jl. Pasteur No. 38 Bandung 40161, Tlpn 022 2038285, Email thomas.mrccc@gmail. com 


\section{Pendahuluan}

Nyeri pascabedah masih merupakan permasalahan bagi dokter anestesi. Nyeri bukan hanya merupakan rangsangan sensorik, namun sebuah pengalaman tidak menyenangkan disertai dengan kerusakan jaringan. ${ }^{1}$ Nyeri pascabedah merupakan salah satu nyeri akut yang timbul karena stimuli yang jelas dan menghilang saat kerusakan jaringan tersebut sudah sembuh. Nyeri akut jika tidak ditangani dengan baik dapat berkembang menjadi nyeri kronik. ${ }^{2}$

MenurutUS InstituteofMedicine, 80\% pasien yang menjalani operasi melaporkan nyeri pascabedah dengan tingkat sedang, berat, atau ekstrem. ${ }^{1}$ Survei skala besar yang dilakukan di Amerika tahun 2013 mendapatkan lebih dari $75 \%$ pasien mengalami nyeri pascabedah sedang hingga berat yang dimulai sesaat setelah operasi dan dapat berlangsung selama perawatan di rumah sakit. ${ }^{3}$ Penatalaksanaan nyeri yang tidak optimal dapat menyebabkan efek negatif seperti peningkatan morbiditas, gangguan fungsi fisik, penurunan kualitas hidup, pemulihan lebih lama, penggunaan opioid berkepanjangan, hingga peningkatan biaya perawatan. ${ }^{4}$

Nyeri pascabedah laparotomi kolesisektomi memiliki derajat nyeri berat yang seharusnya ditangani dengan opioid kuat sebagai analgetik standar. Opioid memberikan efek analgesia yang efektif tanpa mengganggu fungsi proprioseptif atau kekuatan otot., Opioid kuat seperti oksikodon, morfin, fentanil, atau hidromorfon direkomendasikan dalam penanganan nyeri akut sedang hingga berat. Pemilihan opioid merupakan tantangan bagi anestesiologis. Opioid seperti sufentanil dan petidin memiliki keterbatasan dalam penggunaannya, sufentanil dibatasi oleh durasi yang pendek dan petidin menghasilkan metabolit toksik, yaitu norpetidin. ${ }^{8}$ Morfin dan fentanil intravena merupakan salah satu pilihan opioid yang banyak digunakan, namun beberapa penelitian menunjukkan onset morfin yang lebih lambat dan durasi aksi fentanil yang lebih singkat dibanding dengan oksikodon. ${ }^{9}$

Penelitian nyeri akut pascabedah di Korea, Cina, dan Denmark mengemukakan bahwa oksikodon lebih baik menghilangkan nyeri pascabedah dibanding dengan fentanil. Tindakan operasi tersebut meliputi, laparoscopic hysterectomy, laparoscopic myomectomy, laparoscopic cholecystectomy, dan gastrointestinal laparotomy. ${ }^{10-13}$ Penggunaan oksikodon sebagai analgesik pascabedah belum banyak di Indonesia dibanding dengan fentanil. Oleh karena itu, penelitian ini bertujuan membandingkan penggunaan fentanil intravena dengan oksikodon intravena terhadap nyeri pascabedah laparotomi kolesisektomi di RSUP Dr. Hasan Sadikin Bandung.

\section{Subjek dan Metode}

Penelitian ini menggunakan desain uji klinis acak buta ganda (double blind randomized controlled trial).Subjekpenelitianadalahpasien yang menjalani laparotomi kolesistektomi dengan kriteria inklusi status fisik American Society of Anesthesiologists (ASA) I-II, usia 1864 tahun, dan skor general anxiety disorder-7 (GAD-7) $\leq 4$ yang menunjukkan tidak ada kecemasan. Kriteria eksklusi adalah pasien dengan riwayat gangguan kecemasan, riwayat alergi opioid, riwayat nyeri kronis dengan penggunaan opioid sebelumnya. Kriteria pengeluaran adalah pasien yang mengalami syok menetap akibat perdarahan intraoperatif dan pascaoperasi menggunakan obat-obatan inotropik, lama operasi lebih dari 6 jam, atau nyeri pascabedah menetap dinilai dari numeric rating score (NRS) $>3$ setelah diberikan rescue analgetik.

Penentuan besar sampel menggunakan perhitungan perbedaan 2 rerata dengan taraf kepercayaan 95\%, kuasa uji (power test) 80\% dan didapatkan jumlah sampel minimal untuk tiap kelompok adalah 16 orang. Pengambilan sampel dilakukan secara consecutive sampling dan alokasi subjek ke dalam salah satu kelompok dilakukan secara random blok permutasi. 
Penelitian dilakukan di RSUP Dr. Hasan Sadikin Bandung pada bulan Agustus hingga November 2020 setelah mendapatkan persetujuan dari Komite Etik Penelitian Kesehatan Rumah sakit Dr. Hasan Sadikin Bandung/Fakultas Kedokteran Universitas Padjadjaran No: LB.02.01/X.2.2.1/16678/2020. Peserta penelitian yang memenuhi kriteria inklusi dan tidak termasuk kriteria eksklusi diberikan penjelasan mengenai prosedur penelitian serta menandatangani persetujuan informed consent saat praoperasi. Peneliti melakukan randomisasi dalam pemberian obat analgetik secara intravena menjadi 2 kelompok, yaitu kelompok yang mendapatkan intravenous patient controlled analgesia (IV-PCA) fentanil (kelompok F) atau oksikodon (kelompok 0). Seluruh pasien dibawa ke kamar operasi dan dilakukan pemantauan tekanan darah non invasif, elektrokardiogram, laju nadi, laju napas dan saturasi oksigen.

Saat tiba di ruang operasi, anestesi umum dilakukan menggunakan fentanil $2 \mu \mathrm{g} / \mathrm{kgBB}$, propofol $2 \mathrm{mg} / \mathrm{kgBB}$, dan atrakurium $0,5 \mathrm{mg} /$ $\mathrm{kgBB}$. Selama operasi diberikan rumatan gas anestesi dengan $\mathrm{N}_{2} \mathrm{O}: \mathrm{O}_{2}$ 50:50 dan sevoflurane. Pasien diberikan ondansetron $4 \mathrm{mg}$ IV dan ketorolac $30 \mathrm{mg}$ IV saat penutupan luka operasi. Selesai operasi, pasien diberikan reversal pelumpuh otot. Ekstubasi dilakukan setelah pasien sadar penuh dan mulai dipasang alat PCA merk B-Braun untuk analgetik pascabedah. Pasien lalu dipindahkan ke ruang pemulihan dan dilakukan observasi tanda vital.

Analgetik pascabedah yang digunakan adalah continuous IV-PCA oksikodon:fentanil dengan rasio 1:60 dan interval penguncian 15 menit. Kelompok 0 diberikan continuous IVPCA oksikodon $30 \mu \mathrm{g} / \mathrm{kgBB} / \mathrm{jam}$, dosis bolus 30 $\mu \mathrm{g} / \mathrm{kgBB}$, dan kelompok F diberikan continuous IV-PCA fentanil 0,5 $\mu \mathrm{g} / \mathrm{kgBB} / \mathrm{jam}$, dosis bolus $0,5 \mu \mathrm{g} / \mathrm{kgBB}$. Jika pasien mengalami kesakitan di ruang pemulihan diberikan oksikodon 30 $\mu \mathrm{g} / \mathrm{kgBB}$ bolus atau fentanil $0,5 \mu \mathrm{g} / \mathrm{kgBB}$ bolus sesuai dengan kelompok masing-masing. Jika pasien mengalami muntah di ruang pemulihan diberikan ondansetron bolus $4 \mathrm{mg}$. Nyeri diobservasi menggunakan NRS dan efek samping lainnya dicatat dalam waktu 1, 6, 12, dan 24 jam pascabedah. Jika NRS pasien lebih dari 3 setelah pasien menekan bolus PCA maka pasien akan diberikan analgesia tambahan sesuai dengan kelompoknya. Jika masih merasakan nyeri, maka pasien dikeluarkan dari penelitian dan diberikan terapi nyeri lebih lanjut.

Uji statistik penelitian ini menggunakan Uji Mann Whitney pada data numerik. Uji statistik pada data kategorik menggunakan uji chisquare dan Fisher's Exact. Kriteria kemaknaan yang digunakan adalah nilai $\mathrm{p} \leq 0,05$ dianggap signifikan atau bermakna secara statistika. Data hasil penelitian dicatat dan diolah menggunakan program statistical product and service solution (SPSS) versi 22.0 for windows.

\section{Hasil}

Penelitian ini diikuti oleh 34 pasien yang memenuhi kriteria inklusi dan tidak termasuk kriteria eksklusi, namun terdapat 2 pasien dikeluarkan pada follow up karena nyeri pascabedah menetap (NRS 6). Analisis data dilakukan pada 32 pasien, yaitu kelompok $F$ $(\mathrm{n}=16)$ dan kelompok $0 \quad(\mathrm{n}=16)$.

Karakteristik subjek kedua kelompok penelitian berdasar atas usia, jenis kelamin, berat badan, tinggi badan, status gizi, tingkat pendidikan, dan lama operasi tidak berbeda bermakna ( $p>0,05$; Tabel 1).

Nyeri pascabedah yang dinilai dengan NRS antara kedua kelompok berbeda secara signifikan pada jam pertama, jam ke-6, jam ke-12, dan jam ke-24. Kelompok yang mendapatkan oksikodon memiliki nilai skor nyeri yang lebih rendah $(\mathrm{p}<0,05$; Tabel 2). Hasil penilaian NRS jam pertama, jam ke-6, jam ke-12, hingga jam ke-24 untuk tiap-tiap kelompok juga menunjukkan penurunan pada setiap waktu penilaiannya (Gambar).

Penggunaan rescue analgetik pada kelompok 0 lebih sedikit dibanding dengan kelompok F pada jam pertama dan jam ke-6 dengan perbedaan yang signifikan $(\mathrm{p}<0,05)$. Pada jam ke-12 dan jam ke-24, penggunaan rescue analgetik antara kedua kelompok tidak bermakna secara statistik, namun pada 
Tabel 1 Karakteristik Subjek Penelitian

\begin{tabular}{|c|c|c|c|}
\hline \multirow[b]{2}{*}{ Variabel } & \multicolumn{2}{|c|}{ Kelompok } & \multirow[b]{2}{*}{ Nilai p } \\
\hline & $\begin{array}{c}\text { Fentanil (F) } \\
(n=16)\end{array}$ & $\begin{array}{c}\text { Oksikodon }(0) \\
(n=16)\end{array}$ & \\
\hline Usia (tahun) & & & 0,472 \\
\hline Mean \pm Std & $42,16 \pm 11,41$ & $45,33 \pm 13,19$ & \\
\hline Median & 40,63 & 49,96 & \\
\hline Range (min.-maks.) & $27,42-66,33$ & $22,00-62,00$ & \\
\hline Jenis kelamin (n ) & & & 1,000 \\
\hline Laki-laki & 4 & 4 & \\
\hline Perempuan & 12 & 12 & \\
\hline Berat badan (kg) & & & 0,430 \\
\hline Mean \pm Std & $61,81 \pm 7,93$ & $64,06 \pm 7,99$ & \\
\hline Median & 62,00 & 65,50 & \\
\hline Range (min.-maks.) & $48,00-76,00$ & $47,00-75,00$ & \\
\hline Tinggi badan $(\mathrm{cm})$ & & & 0,415 \\
\hline Mean \pm Std & $160,13 \pm 5,05$ & $161,63 \pm 5,21$ & \\
\hline Median & 159,00 & 160,00 & \\
\hline Range (min.-maks.) & $153,00-170,00$ & $154,00-170,00$ & \\
\hline Status gizi (n) & & & 1,000 \\
\hline Gizi lebih & 6 & 6 & \\
\hline Gizi baik & 10 & 10 & \\
\hline Tingkat pendidikan (n) & & & 0,543 \\
\hline SD & 1 & 3 & \\
\hline SLTP & 5 & 5 & \\
\hline SLTA & 9 & 6 & \\
\hline Perguruan tinggi & 1 & 2 & \\
\hline Lama operasi (jam) & & & 0,906 \\
\hline Mean \pm Std & $3,41 \pm 0,35$ & $3,44 \pm 0,41$ & \\
\hline Median & 3,50 & 3,50 & \\
\hline Range (min.-maks.) & $3,00-4,00$ & $3,00-4,25$ & \\
\hline
\end{tabular}

Keterangan: data numerik nilai p diuji dengan Uji Mann Whitney karena data tidak berdistribusi normal. Data kategorik nilai p dihitung berdasar atas uji chi-square dan Uji Fisher's Exact. Nilai kemaknaan berdasar atas nilai $\mathrm{p}<0,05$

kelompok F dapat dilihat terdapat subjek yang menggunakan rescue analgetik, sedangkan pada kelompok 0 tidak ada (Tabel 3).

Penelitian ini menunjukkan tidak terdapat perbedaan kejadian mual muntah pascabedah antara kedua kelompok baik pada jam pertama ataupun setiap waktu evaluasi hingga jam ke24. Dalam pemantauan juga tidak terdapat efek samping distres pernapasan yang terjadi, sedangkan pusing, sakit kepala, atau pruritus tidak berbeda bermakna pada kedua kelompok $(\mathrm{p}=1,000 ; \mathrm{p}=0,333 ; \mathrm{p}=1,000$ berurutan).

\section{Pembahasan}

Hasil penelitian ini menunjukkan efek 
Tabel 2 Perbandingan Nyeri antara Kelompok Fentanil dan Kelompok Oksikodon Pascabedah Laparotomi Kolesisektomi

\begin{tabular}{lccc}
\hline \multirow{2}{*}{ Skor Nyeri (NRS) } & \multicolumn{2}{c}{ Kelompok } & \multirow{2}{*}{ Nilai p } \\
\cline { 2 - 3 } & $\begin{array}{c}\text { Fentanil (F) } \\
\text { (n=16) }\end{array}$ & $\begin{array}{c}\text { Oksikodon (0) } \\
\text { (n=16) }\end{array}$ & \\
\hline Jam pertama & $4,94 \pm 0,68$ & $3,001^{*}$ \\
Mean \pm Std & 5 & & \\
Median & $4-6$ & $3-4$ & \\
Range (min.-maks.) & & & $0,001^{*}$ \\
Jam ke-6 & $3,50 \pm 0,63$ & $2,69 \pm 0,48$ & \\
Mean \pm Std & 3 & 3 & \\
Median & $3-5$ & $2-3$ & $0,001^{*}$ \\
Range (min.-maks.) & & & \\
Jam ke-12 & $2,75 \pm 0,78$ & $1,56 \pm 0,51$ & \\
Mean \pm Std & 3 & 2 & \\
Median & $2-4$ & $1-2$ & $0,001^{*}$ \\
Range (min.-maks.) & & & \\
Jam ke-24 & $2,06 \pm 0,58$ & $1,06 \pm 0,77$ & \\
Mean \pm Std & 2 & 1 & \\
Median & $1-3$ & $0-2$ & \\
Range (min.-maks.) &
\end{tabular}

Keterangan: Untuk data numerik nilai p diuji dengan uji Mann Whitney karena data tidak berdistribusi normal. Nilai kemaknaan berdasarkan nilai $\mathrm{p}<0,05$. Tanda* menunjukkan nilai $\mathrm{p}<0,05$ artinya signifkan atau bermakna secara statistik

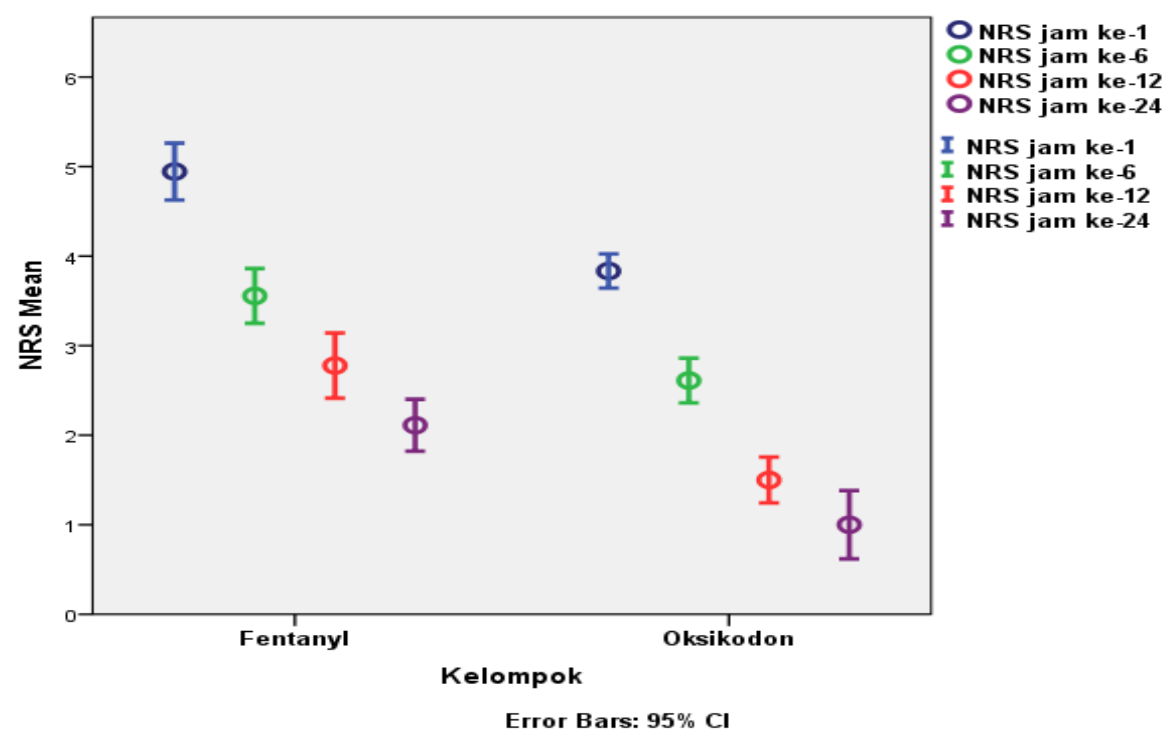

Gambar Perbandingan NRS antara Kelompok Fentanil dan Kelompok Oksikodon Pascabedah Laparotomi Kolesisektomi 
Tabel 3 Perbandingan Kebutuhan Rescue Analgetik antara Kelompok Fentanil dan Kelompok Oksikodon Pascabedah Laparotomi Kolesisektomi

\begin{tabular}{lccc}
\hline \multirow{2}{*}{ Rescue Analgetik } & \multicolumn{2}{c}{ Kelompok } & Nilai p \\
\cline { 2 - 3 } & $\begin{array}{c}\text { Fentanil (F) } \\
(\mathbf{n = 1 6 )}\end{array}$ & $\begin{array}{c}\text { Oksikodon (0) } \\
(\mathbf{n = 1 6 )}\end{array}$ & $0,012^{*}$ \\
\hline $\begin{array}{l}\text { Jam pertama } \\
\text { Ya }\end{array}$ & 13 & 6 & \\
Tidak & 3 & 10 & $0,022^{*}$ \\
Jam ke-6 & & & \\
Ya & 8 & 2 & 0,226 \\
Tidak & 8 & 14 & \\
Jam ke-12 & 3 & & 0,484 \\
Ya & 13 & 0 & \\
Tidak & & 16 & \\
Jam ke-24 & 2 & 0 & \\
Ya & 14 & 16 & \\
Tidak & & & \\
\hline
\end{tabular}

Keterangan: Data disajikan dalam jumlah subjek (\%). Data kategorik nilai p dihitung berdasar atas uji chi-square untuk jam pertama dan ke-6 dengan alternatif Uji Fisher's Exact untuk jam ke-12 dan ke-24 karena syarat dari chi-square tidak terpenuhi. Nilai kemaknaan berdasar atas nilai $\mathrm{p}<0,05$. Tanda* menunjukkan nilai $\mathrm{p}<0,05$ artinya signifkan atau bermakna secara statistik

analgesia pada pasien pascabedah laparotomi kolesistektomi yang mendapatkan continuous IV-PCA oksikodon lebih baik dibanding dengan IV-PCA fentanil. Karakteristik subjek penelitian ini berdasar atas usia, jenis kelamin, berat badan, tinggi badan, status gizi, tingkat pendidikan, dan lama operasi antara kedua kelompok tidak menunjukkan perbedaan bermakna $(p>0,05)$. Hal ini menunjukkan bahwa sampel penelitian ini homogen dan layak untuk dibandingkan.

Oksikodon adalah hasil sintesis thebaine yang merupakan opioid poten yang baik untuk nyeri viseral maupun somatik. ${ }^{14}$ Oksikodon dan fentanil merupakan opioid kuat yang bekerja pada reseptor membran presinap terminal saraf pusat. Pemberian oksikodon menunjukkan hasil yang lebih baik daripada fentanil karena oksikodon menghambat reseptor $\mu$ dan $\kappa$, sedangkan fentanil hanya menghambat di reseptor $\mu{ }^{15}$ Fentanil bekerja pada reseptor $\mu$ yang lebih memberikan efek analgesia pada nyeri yang bersifat tajam seperti luka pembedahan. Oksikodon dengan dual reseptor juga memberikan efek analgesia pada nyeri luka pembedahan. ${ }^{16,17}$ Selain itu, aksi agonis pada reseptor $\kappa$ menyebabkan oksikodon berkerja baik untuk nyeri viseral pada operasi abdominal yang cenderung memiliki insisi kecil dengan efek nyeri viseral yang besar. Reseptor ini terdapat pada akhir saraf peritonium dan dorsal horn dari spinal cord. ${ }^{18}$

Fentanil memiliki durasi aksi yang pendek, onset kerjanya 30 detik dengan efek maksimal didapat setelah 5 menit pemberian sehingga dibutuhkan dosis yang lebih tinggi untuk mendapatkan efek analgesia adekuat. ${ }^{15,19}$ Oksikodon merupakan opioid semisintetik kuat yang bekerja sebagai agonis pada sistem saraf pusat, perifer, maupun autonom. Oksikodon memiliki onset analgesia yang hampir sama dengan fentanil, 2-3 menit, dengan durasi yang lebih lama (t1/2 4-5 jam). ${ }^{15}$

Pada penelitian ini, penilaian nyeri dengan 
skor NRS dilakukan pada jam pertama, ke-6, ke-12, dan ke-24 pascabedah. Nilai NRS pada jam pertama hingga jam ke-24 menunjukkan hasil yang signifikan dengan NRS yang lebih rendah pada kelompok oksikodon dibanding dengan fentanil dengan rerata NRS pada jam pertama 4,94 $\pm 0,68$ pada kelompok fentanil dan 3,88 $\pm 0,34$ kelompok oksikodon. Evaluasi pada 24 jam pascabedah menunjukkan NRS kelompok fentanil 2,06 $\pm 0,58$ yang lebih tinggi daripada kelompok oksikodon 1,06 $\pm 0,77$.

Penelitian yang ada sebelumnya membandingkan pemakaian oksikodon dan fentanil pada operasi ortopedi. Oksikodon memiliki efek analgesia yang lebih baik daripada fentanil untuk nyeri somatik pada pasien pascabedah total knee replacement. Kebutuhan opioid tambahan setiap 6 jam hingga 48 jam pascabedah lebih rendah pada kelompok oksikodon. ${ }^{6}$ Penelitian lain pada pasien pascabedah total hip replacement, penilaian NRS kelompok oksikodon didapati lebih rendah secara signifikan. Rerata NRS yang diukur pascabedah $3,48 \pm 1,50$ pada kelompok oksikodon dan 4,96 $\pm 1,64$ pada kelompok fentanil $(\mathrm{p}=0,003){ }^{20}$

Penelitian di Korea pada pasien laparoskopi histerektomi menunjukkan oksikodon PCA intravena dengan perbandingan potensi fentanil:oksikodon 1:75 memberikan efek analgesia yang lebih superior. Penilaian NRS pada 4 jam dan 8 jam pascabedah lebih rendah pada kelompok oksikodon $(\mathrm{p}<0,001){ }^{21}$ Penelitian lain pada pasien pascalaparoskopi gastrektomi dengan PCA intravena fentanil:oksikodon rasio 1:55 mendapati nyeri yang lebih rendah pada kelompok oksikodon. Nilai NRS pada kelompok oksikodon saat dinilai di PACU 3,6 $\pm 1,4$ lebih rendah dibanding dengan dengan kelompok fentanil $4,4 \pm 2,0$ $(\mathrm{p}=0,031){ }^{22}$

Pada awalnya, penelitian-penelitian yang menggunakan oksikodon PCA intravena hanya memberikan dosis bolus $2 \mathrm{mg}$ diikuti PCA berdasar atas keinginan pasien. ${ }^{23}$ Akan tetapi, penelitian lanjutan menunjukkan pada pemberian oksikodon dengan PCA intravena loading dose $0,1 \mathrm{mg} / \mathrm{kgBB}$ diikuti continuous intravenous infusion menghasilkan waktu kestabilan konsentrasi plasma lebih cepat dibanding dengan pemberian bolus dosis tunggal, yaitu 9-14 jam. Kadar minimum effective analgesic concentration (MEAC) oksikodon akan tercapai dalam waktu 2 jam. ${ }^{23,24}$

Protokol IV-PCA fentanil yang ada kebanyakan menggunakan dosis bolus $2 \mu \mathrm{g} /$ $\mathrm{kgBB}$ dengan dosis rescue $15 \mu \mathrm{g}$ dan continuous intravenous infusion $15 \mu \mathrm{g} / \mathrm{jam}$. Dengan regimen tersebut, MEAC fentanil terjadi hingga kurang lebih 6 jam setelah PCA dimulai dan waktu untuk mencapai kestabilan konsentrasi plasmanya hingga 18,5 jam. Jika dibandingkan, MEAC dan waktu untuk mencapai kestabilan konsentrasi plasma oksikodon lebih cepat dibanding dengan fentanil. ${ }^{24} \mathrm{Hal}$ ini dapat menjadi dasar yang menyebabkan penilaian nyeri pada pasien yang mendapat oksikodon lebih rendah daripada fentanil hingga 24 jam pascabedah.

Pada penelitian ini, rescue analgetik pada jam pertama dan jam ke-6 kelompok oksikodon lebih rendah daripada kelompok fentanil ( $\mathrm{p}=, 012 ; \mathrm{p}=0,022$, berurutan). Pada jam ke-12 dan jam ke-24 tidak ada perbedaan bermakna pada pemakaian rescue analgetik. Walaupun demikian, masih terdapat subjek pada kelompok fentanil yang menggunakan rescue analgetik dan kelompok oksikodon tidak. Penelitian ini sesuai dengan penelitian pascalaparoskopi gastrektomi di Korea yang menunjukkan kebutuhan rescue analgetik pada kelompok oksikodon juga lebih rendah dibanding dengan kelompok fentanil $(12 \%$ vs $37 \%, \mathrm{p}=0,005) .{ }^{22}$ Penggunaan rescue analgetik kelompok fentanil lebih tinggi disebabkan oleh penurunan efek analgesia yang lebih cepat. Kelarutan dalam lemak yang lebih tinggi dibanding dengan oksikodon membuat fentanil lebih cepat mengalami redistribusi. ${ }^{16,17}$

Efek samping penggunaan PCA opioid adalah mual dan muntah, pruritus, depresi pernapasan, sedasi, hingga retensi urin. ${ }^{2,17}$ Mual dan muntah merupakan efek samping terbanyak pada pasien yang mendapat PCA intravena pascabedah. Derajatnya bergantung pada jenis prosedur operasi, obat yang digunakan, kecemasan, bahkan nyeri. 
Opioid menstimulasi triger kemoreseptor pada medula yang menyebabkan kejadian tersebut.,19 Penelitian ini menunjukkan tidak terdapat perbedaan kejadian mual muntah pascabedah maupun efek samping lain seperti pusing, sakit kepala, dan pruritus pada kedua kelompok serta tidak ditemukan efek samping distres pernapasan yang terjadi. Akan tetapi, penilaian kejadian efek samping pada penelitian ini belum dapat disimpulkan. Perlu penelitian lanjutan untuk mengetahui perbedaan kejadian efek samping penggunaan fentanil dengan oksikodon.

Keterbatasan penelitian adalah tidak dilakukan pengukuran ambang toleransi nyeri pada pasien sebelum operasi.

\section{Simpulan}

Pemberian IV-PCA oksikodon memiliki efek analgetik lebih baik yang dinilai dari skor NRS lebih rendah daripada pemberian IV-PCA fentanil pada pasien pascabedah laparotomi kolesistektomi.

\section{Daftar Pustaka}

1. Vrooman BM, Rosenquist RW. Chronic pain management. Dalam: Butterworth JF, Mackey DC, Wasnick DJ, penyunting. Morgan \& Mikhail's clinical anesthesiology. Edisi ke-6. New York: Mc Graw Hill; 2018. hlm. 1024-85.

2. Malek J, Sevcik P, Bejsovec D, Gabrhelik T, Hnilicova M, Krikava I, penyunting. Postoperative analgesia. Postoperative Pain Management. Edisi ke-3. Praha: Mlada Fronta; 2017.

3. Gan TJ, Habib AS, Miller TE, White $\mathrm{W}$, Apfelbaum JL. Incidence, patient satisfaction, and perceptions of postsurgical pain: results from a US national survey. Curr Med Res Opin. 2014;30(1):149-60.

4. Gan TJ. Poorly controlled postoperative pain: prevalence, consequences, and prevention. J Pain Res. 2017;10:2287-98.

5. Bonham CA, Oberhelman HA, Lemmens HJM. Billiary tract surgery. Dalam: Jaffe
AR, Schmiesing CA, Golianu B, penyunting. Anesthesiologist's manual of surgical procedure. Edisi ke-6. Philadelphia: Lippincott Williams \& Wilkins; 2019. hlm. 908-12.

6. Yang SA, Kim KS, Kang HY. Oxycodone vs fentanyl in the treatment of early post-operative pain after total knee replacement: randomized controlled trial. Anesth Pain Med. 2016;11:349-53.

7. Kokki H, Kokki M, Sjovall S. Oxycodone for the treatment of postoperative pain. Expert Opin. Pharmacother. 2012;13(7):1045-58.

8. Hastie BA, Gilson AM, Maurer MA, Cleary JF. An examination of global and regional opioid consumption trends 1980-2011.

J Pain Palliat Care Pharmacother. 2014;28:259-75.

9. Raff M, Belbachir A, El-Tallawy S, Ho KY, Naglaton E, Salti A, dkk. Intravenous oxycodone versus other intravenous strong opioids for acute postoperative pain control: a systematic review of randomized controlled trials. Pain Ther. 2019;8:19-39.

10. Hwang BY, Kwon JY, Kim E, Lee DW, Kim TK, Kim HK. Oxycodone vs fentanyl patient-controlled analgesia after laparoscopic cholecystectomy. Int J Med Sci. 2014;11(7):658-62.

11. Kim NS, Kang KS, Yoo SH, Chung JH, Chung JW, Seo Y, dkk. A comparison of oxycodone and fentanyl in intravenous patient controlled analgesia after laparoscopic hysterectomy. Korean J Anesthesiol. 2015;68(3):261-6.

12. Park JH, Lee C, Shin Y, An JH, Ban JS, Lee JH. Comparison of oxycodone and fentanyl for postoperative patient-controlled analgesia after laparoscopic gynecological surgery. Korean J Anesthesiol. 2015;68(2):153-8.

13. Ding Z, Wang K, Wang B, Zhou N, Li H, Yan B. Efficacy and tolerability of oxycodone versus fentanyl for intravenous patientcontrolled analgesia after gastrointestinal laparotomy: a prospective, randomized, double-blind study. Medicine (Baltimore). 
2016;95(39):e4943.

14. Kwon YS, Jang JS, Lee NR, Kim SS, Kim YK, Hwang BM, dkk. A comparison of oxycodone and alfentanil in intravenous patient-controlled analgesia with a timescheduled decremental infusion after laparoscopic cholecystectomy. Pain Res Manag. 2016;7868152:1-8.

15. Drewes AM, Jensen RD, Nielsen LM, Droney J, Christrup LL, Arendt-Nielsen L. Differences between opioids: pharmacological, experimental, clinical and economical perspectives. Br J Clin Pharmacol. 2013;75(1):60-78.

16. Olkkola KT, Kontinen VK, Saari TI, Kalso EA. Does the pharmacology of oxycodone justify its increasing use as an analgesic? Trends Pharmacol Sci. 2013:34(4);206-14.

17. Zhang C, Ding J, Wang B, Chen P. A single intravenous injection of oxycodone hydrochloride in the treatment of acute post-operative pain after laparoscopic rectal tumor resection. BIO Web Conf. 2017;8:01055.

18. Kinnunen M, Pllrainen P, Kokki H, Lammi P, Kokki M.Updated clinical pharmacokinetics and pharmacodynamics of oxycodone. Clin Pharmacokinet. 2019;58(6):705-25.

19. Hurley RW, Elkassabany NM, Wu CL. Acute postoperative pain. Dalam: Gropper MA, Cohen NH, Eriksson LI, Fleisher LA, Leslie $\mathrm{K}$, Wiener-kronish JP, penyunting. Miller's anesthesia. Edisi ke-9. Philadelphia: Elsevier; 2020. hlm. 2614-38.

20. Kim MY, Ahn SE, Shin E, Park SW, Choi $\mathrm{JH}$, Kang HY. Comparison of analgesic efficacy of oxycodone and fentanyl after total hip replacement surgery. Medicine. 2018;97:49-53.

21. Kim NS, Lee JS, Park SY, Ryu A, Chun HR, Chung HS, dkk. Oxycodone versus fentanyl for intravenous patient controlled analgesia after laparoscopic supracervical hysterectomy. Medicine. 2017;96:10(e6286).

22. Koh JC, Kong HJ, Kim MH, Hong JH, Seong $\mathrm{H}$, Kim NY, dkk. Comparison of analgesic and adverse effects of oxycodone and fentanyl based patient controlled analgesia in patients undergoing robot assisted laparoscopic gastrectomy using a 55:1 potency ration of oxycodone to fentanyl: a retrospective study. J Pain Res. 2020;13:2197-204.

23. Kokki M, Broms S, Eskelinen M, Rasanen I, Ojanpera I, Kokki H. Analgesic concentrations of oxycodone - a prospective clinicalPK/PD study in patients with laparoscopic cholecystectomy. BCPT. 2012;110:469-75.

24. Choi BM. A new therapeutic option for postoperative pain management with oxycodone HCI injection. Korean J Anesthesiol. 2016;69(3):211-8. 